\title{
Experimental Method for Examination of State Dependent Friction
}

\author{
FERENC SAFrANYIK ${ }^{1}$, ATtila CsatáR ${ }^{2}{ }^{*}$, AtTila VARgA ${ }^{1}$
}

\begin{abstract}
The phenomenon of friction reduces efficiency of almost all machines in practice. In order to reduce the deficits, we have to understand this phenomenon and have to take it into consideration during design in all cases. Nevertheless, in certain cases describing of a friction process is very difficult, because it depends on a lot of parameters. In case of polymers, granular materials or in geology, the rate and state dependent friction have great importance. In this paper, velocity and time dependent friction is examined with the help of a direct shear apparatus, which was developed in our earlier work.
\end{abstract}

Keywords: state dependent friction, velocity dependent friction, direct shear test

\section{Introduction}

Coulomb was the first researcher who examined the friction process about three centuries ago and discovered that the kinetic friction does not depend on the shear velocity (Dowson, 1979). Later, further researches showed that this phenomenon depends on several parameters, such as materials, roughness and temperature. It is also remarkable that friction may be velocity dependent. In some cases, due to the wide variety of parameters, the description of a friction process is very difficult. In geology, mining and earthquake science, in case of polymers, granular materials or other special materials the rate and state dependent friction (creep and relaxation) have great importance. Friction is a form of dissipation; therefore it is the subject of thermodynamics. However, only few researchers investigate the thermodynamic aspects of time dependent of friction (Mitsui et al., 2014; Ruina, 1983; Ván, 2010). The aim of our work was the development of a direct shear testing apparatus by which we can examine the rate and state

\footnotetext{
* Corresponding author. E-mail: csatar.attila@gmgi.hu

1 Szent István University, Department of Mechanics and Technical Drawing

2 Montavid Thermodynamic Research Group, Hungary
} 
dependent friction of polyamide and steel. This shear apparatus is connected to the INSTRON 5581 type universal material testing machine and it is suitable for shearing with different (maybe very low) velocity and on different normal loads. Based on the results of experimental measurements, the previously developed apparatus is suitable to examine time dependent and velocity dependent properties of friction.

\subsection{Direct shear test}

One of the most important things for the description of a friction process is the knowledge of the shear strength, which means the relationship between the displacement and the shear force (Csatár et al., 2013). The shear strength can be determined by using direct shear test; then a fixed and a moveable surface are pressed together with constant normal load, meanwhile moving on each other. During the tests, the shear force is measured as a function of displacement.

Shear tests at various normal loads allow to observe a linear correlation between the shear strength and the normal strength. The slope of this line is the friction coefficient concerning the materials, the designate constant of this line is the cohesion between the surfaces. The shear strength is based on the Mohr-Coulomb equation (Dowson, 1979):

$$
\tau(\varphi)=c+\sigma_{n} \cdot \operatorname{tg} \varphi,
$$

where $c$ is the cohesion, $\varphi$ is the friction angle between the surfaces (Figure 1).

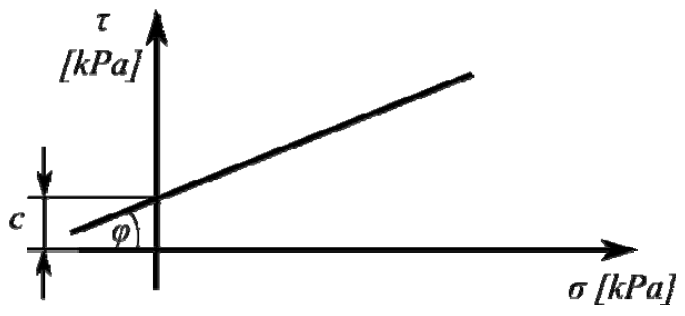

Fig. 1. The Mohr-Coulomb yield function

The residual strength is:

$$
\tau\left(\varphi_{r}\right)=\sigma_{n} \cdot \operatorname{tg} \varphi_{r}
$$

where $\varphi_{r}$ is the residual friction angle between the surfaces. 


\subsection{Time and velocity dependent experiments}

The friction phenomenon may be time and velocity dependent under particular conditions. This phenomenon is modeled by the so-called rate and state dependent friction laws. It plays a particularly important role in geology: faults may undergo decelerating postseismic slip (afterslip), long term stable slip (fault creep) in the absence of earthquake instability, and perhaps slow postseismic slip (Dietrich, 1981). That was the main reason why Dietrich et al. examined the shearing process with clean surfaces of granite (Dietrich, 1979; Dietrich et al., 1994) and with a layer of simulated fault gouge consisting of crushed and sieved granite (Dietrich, 1981). The crushed granite fractions were $<250 \mu \mathrm{m}$ in all cases. These tests were done with various shear parameters (normal load, shear velocity). The sample assembly consists of three blocks, sandwich type direct shear configuration (Figure 2). In this layout, there are two contact surfaces, which have $50 \times 50$ $\mathrm{mm}$ dimensions. The vertical load causes differences in the vertical elastic displacement within the blocks; however, this arrangement is suitable to reduce these differences. With this type of direct shear arrangement, the vertical and horizontal hydraulic rams are suitable to independently control the shear and normal stresses. Motion of the vertical ram (and the displacement) was generally servo-controlled on displacement using a highspeed servo control valve. The minimal shear velocity was $0.1 \mu \mathrm{m} / \mathrm{s}$, therefore, to these servo control valves (Dietrich, 1981).

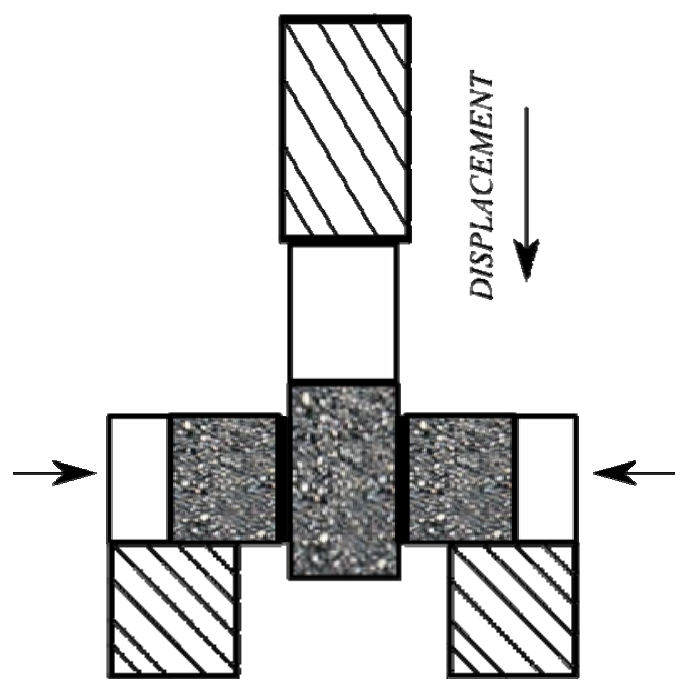

Fig. 2. The sample assembly by Dietrich 
There are three different settings carried out in the tests: constant velocity, multiple velocity and time dependent shear tests. The first, i.e. the constant velocity tests were made at $2.5 \mu \mathrm{m} / \mathrm{s}$ (Figure 3/a). In the multiple velocity tests have three steps. In the first step the shear velocity was constant for a predetermined displacement and in the following step suddenly changed by a factor of 10, held constant for another displacement then changed again and so on (Figure 3/b). The latest types of shear tests were the time dependency tests, where constant velocity shear was interrupted at a specified displacement and the control displacement is held at zero for a specified time interval (Figure 3/c) (Dietrich, 1981).

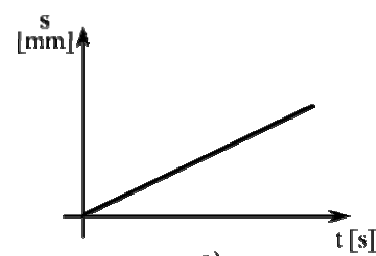

a)

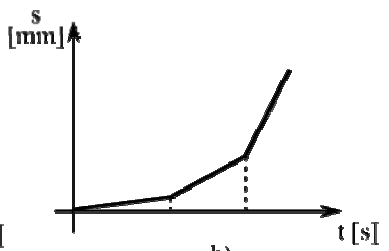

b)

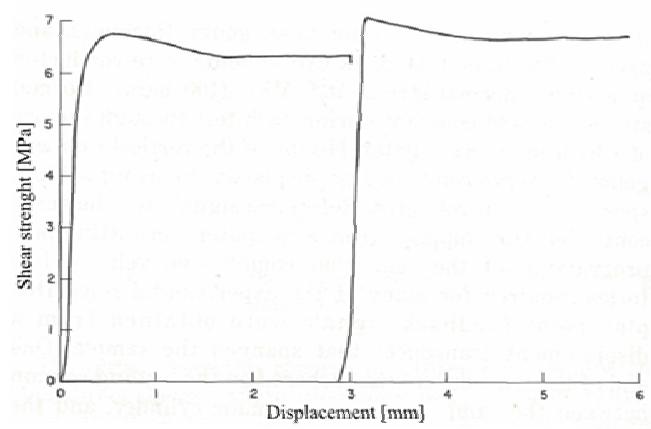

d)

Fig. 3. a) Constant velocity test; b) Multiple velocity test; c) Time dependency test; d) Shear diagram with constant velocity and normal stress

The aim of the constant velocity tests were to examine the overall form of stress-displacement curves (Figure 3/d) to permit reasonably direct comparison to be made for the control of strength by the fault parameters. Based on these curves, the shear strength increases to an initial peak, which is followed by a slow displacement weakening and then stabilization at residual shear strength (Figure 3/d). If the shear stress cycles to zero after reaching residual strength, it acts to restore the peak in the stressdisplacement curves. This cycling increases the total displacement and also the peak and residual strength (Dietrich, 1981).

The purpose of the multiple velocity tests was to look for variations of strength as a function of velocity. A step increase of shear velocity results in an immediate jump in frictional coefficient, followed by displacement dependent decay and stabilization at a new steady-state friction. The reverse is seen if the shear speed is decreased (Figure 4). 


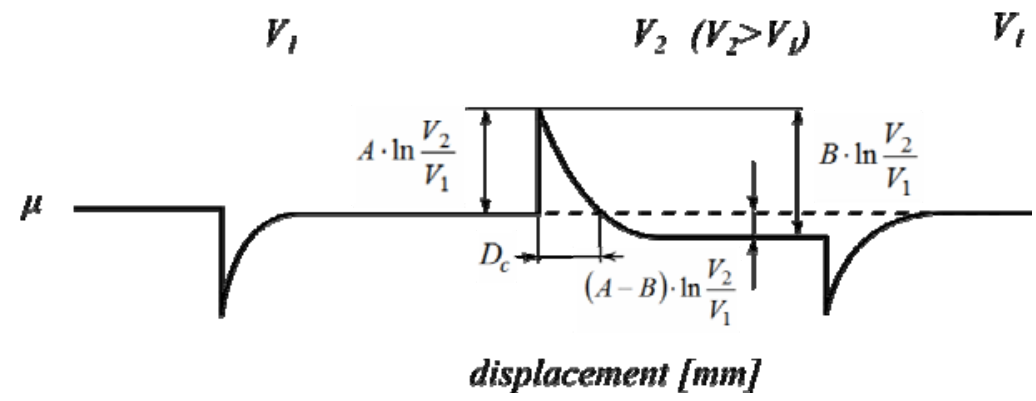

Fig. 4. Effect of steps in shear speed on a friction coefficient

Dietrich and Kilgore (1994) formulated an empirical law for fault tests. This formulation provides a descriptive framework for the interpretation of the transient shearing phenomenon. The coefficient of friction can be represented:

$$
\mu=\frac{\tau}{\sigma}=\mu_{0}+A \cdot \ln \left(\frac{V}{V^{*}}+1\right)+B \cdot \ln \left(\frac{\Theta}{\Theta^{*}}+1\right),
$$

where $\tau$ and $\sigma$ are shear and normal stress, $V$ is a shear speed and $\Theta$ is a state variable. Parameters $\mu_{0}, A$ and $B$ are experimentally determined constants and $V^{*}$ and $\Theta *$ are normalizing constants (Dietrich et al., 1994). A thermodynamic generalization of this empirical rate and state dependent friction law is given in Ván et al., 2015.

\section{Materials and Methods}

The design was made on the basis of Dietrich's vertical shear apparatus (Dietrich, 1981). In case of Dietrich's arrangement, the displacement was vertical and the normal force was horizontal, while in our case the normal force is vertical and it is provided by an INSTRON 5581 type universal material testing machine. During shearing, the contact surface area does not change; one of the probes must be longer. We decided on a box type layout, because this apparatus must be suitable for shearing also granular materials; for this reason this must contain a fixed, loaded part and a moving part. These parts are suitable for fixing the probes. The shear force was measured by a load cell, which is located at the holding point of the fixed part; the displacement was measured by an inductive displacement transducer at the moving part. The displacement was provided by a stepper motor (Figure 5). 


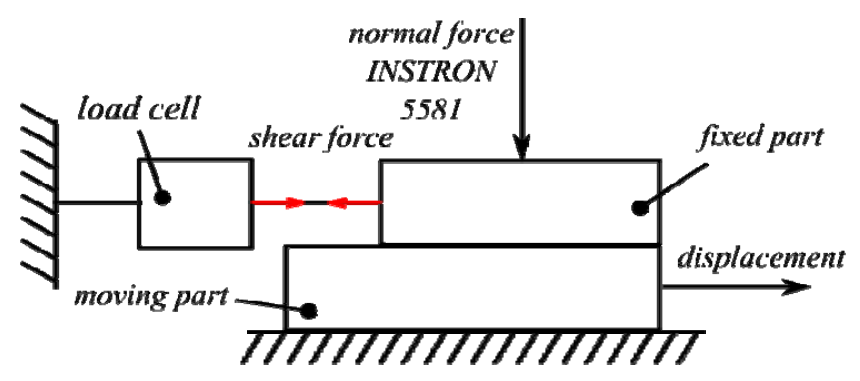

Fig. 5. The sample assembly

To reduce the friction force between the moving part and the baseplate, linear bearing was used. Owing to the stepper motor and the control electronics, very low shear velocity can be set. The rotation of the stepper motor is transformed to linear displacement by a screw shaft; this connects to the stepper motor with a cased coupling.

The parts were designed based on Dietrich's experiments (Dietrich, 1981): During his tests with granite, the largest shear strength was $10 \mathrm{MPa}$, we supposed this value to be maximum stress. Before designing of the geometry, we had to choose the suitable stepper motor based on the torque demand of shearing. For this we needed to know the parameters of the screw shaft and the maximum shear force, because the maximum torque is:

$$
M_{\max }=F_{\max } \cdot \frac{d_{2}}{2} \cdot \operatorname{tg}\left(\alpha+\rho^{\prime}\right)
$$

where $F_{\max }$ is the maximum load on the shaft during shearing, $d_{2}$ is the effective diameter of the screw thread, $\alpha$ is the profile angle of the metric thread and $\rho^{\prime}$ is the modified friction angle. In case of $350 \mathrm{~mm}^{2}$ shear surface and $10 \mathrm{MPa}$ maximum stress during shearing, the maximum shear force is:

$$
F_{\max }=10 \mathrm{MPa} \cdot 350 \mathrm{~mm}^{2}=3500 \mathrm{~N} \text {. }
$$

M8 $\times 0.75$ metric fine thread was chosen to the screw shaft. With this according to Eq. 5 the torque demand of shearing is $M_{\max }=5.2 \mathrm{Nm}$. Based on the torque demand, a XINJE 86BYGH3125 3-phase stepper motor with a torque of $6 \mathrm{Nm}$ was chosen, because of its very low speed and small size. With the knowledge of dimensions of the stepper motor, the geometry of the apparatus can be designed (Figure 6). 

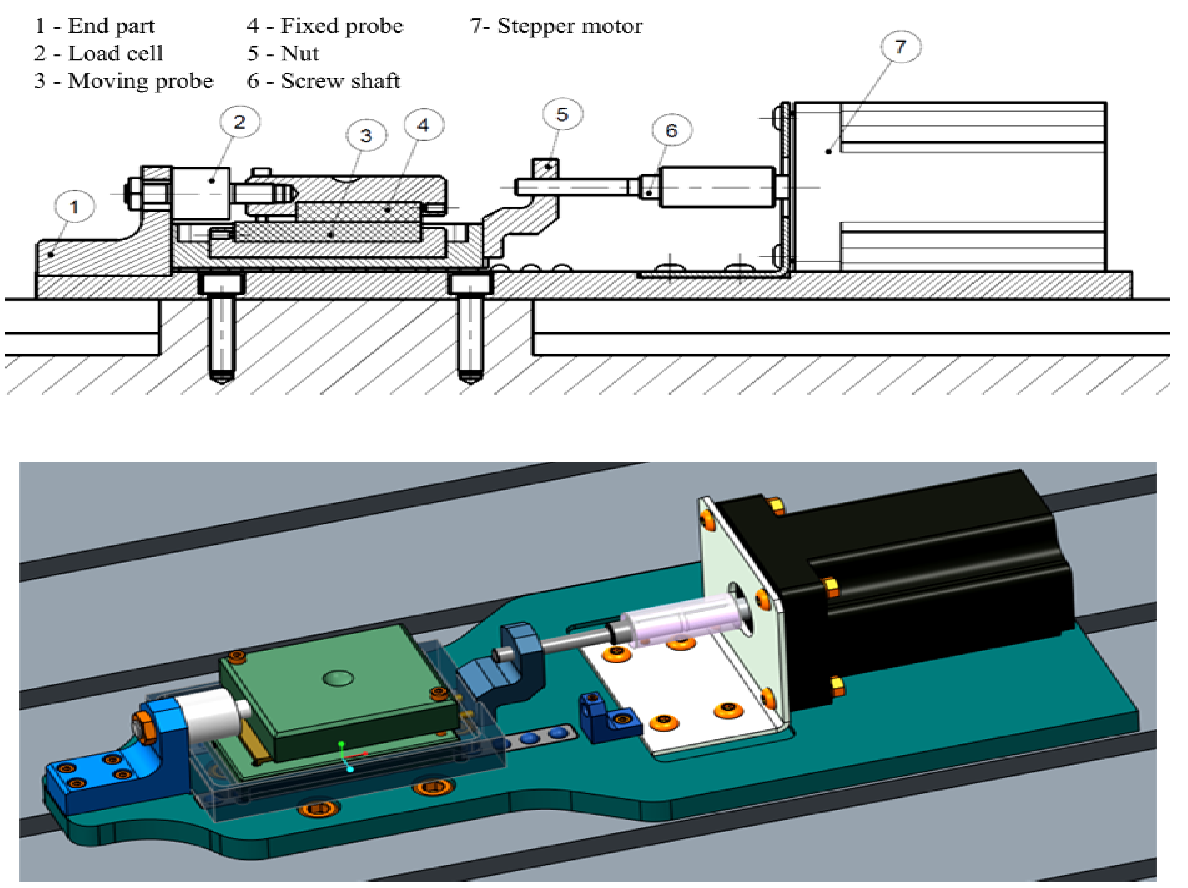

Fig. 6. The test assembly and the 3D model of the apparatus

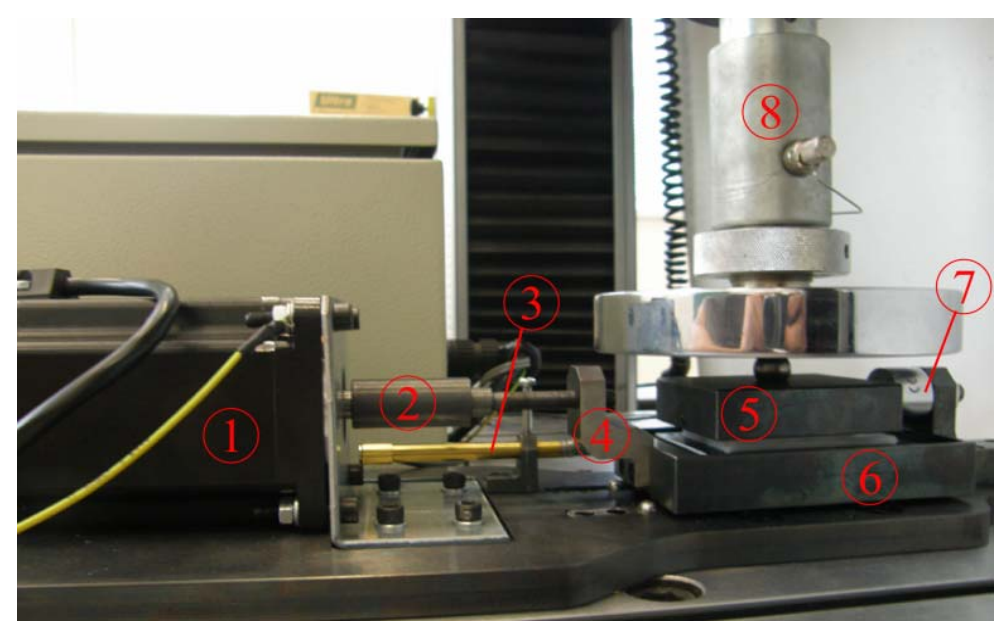

Fig. 7. The finished apparatus

In Figure 7 the finished shear apparatus can be seen: 1 - stepper motor; 2 - screw shaft and cased coupling; 3 - displacement transducer; 4 - nut; 5 - fixed part; 6 - moving part; 7 - load cell; 8 - INSTRON 5581. The normal 
load was provided by the INSTRON 5581 type universal material testing machine; the load was transferred trough a steel ball, which ensures the punctual load to the fixed part.

\subsection{The controlling electronics}

The chosen motor is a three phase stepper motor that divides a full rotation into a number of equal steps; therefore, in order to achieve the minimum speed, a XINJE DP-7022 digital stepper drive was used. With its microstep function, no more than $65535 \mathrm{step} /$ rotation can be set up, which ensures the low and exact angular velocity of the stepper motor. Microstepping is a way of moving a stepper smoothly. Due to all square-impulse, the stepper motor rotates with an angle which depends on the microsteps, therefore the number of the impulses determines the full rotation angle and their frequency determines the angular velocity of the rotation. The motor and the user interface are controlled by own developed electronics which is based on an 8 bit PICF18F4550 microcontroller. The user interface consists

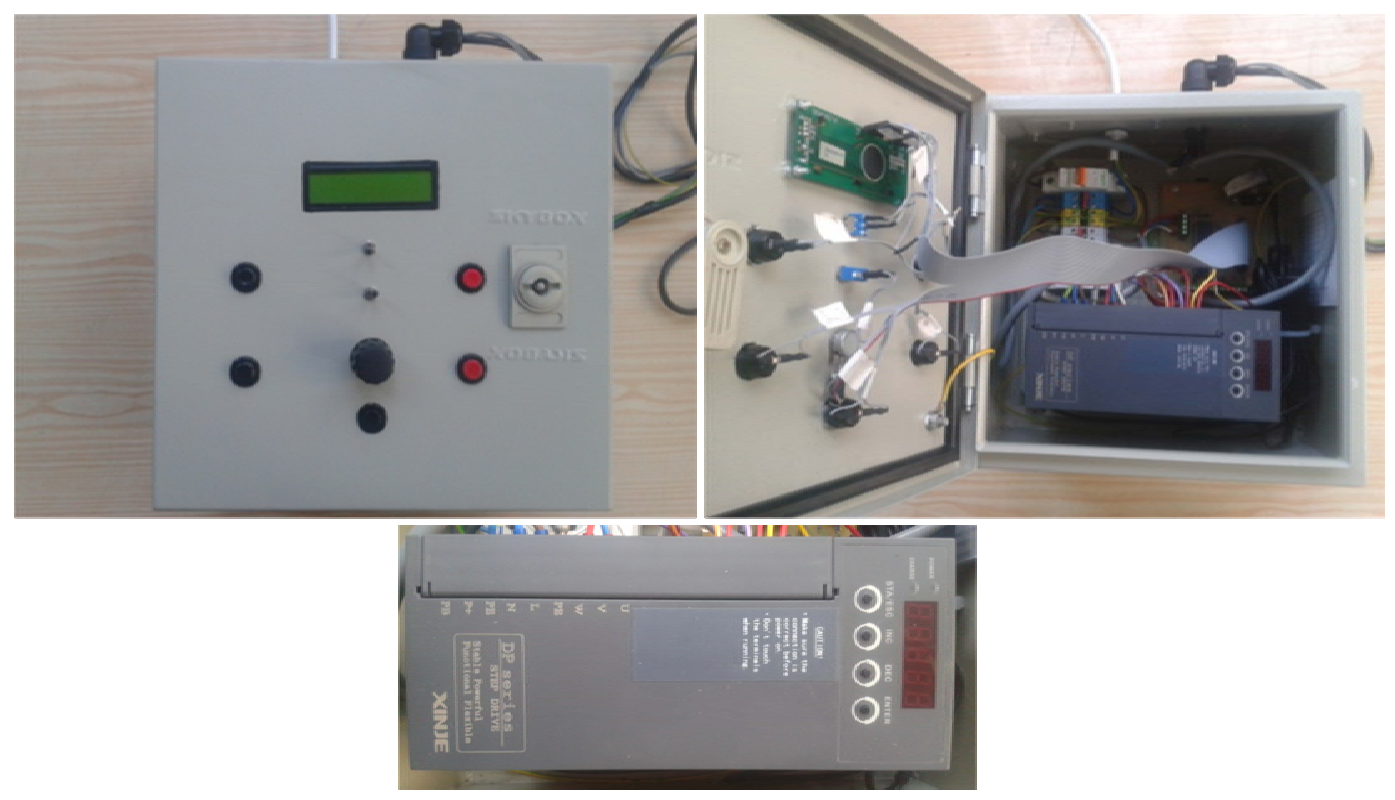

Fig. 8. The controlling electronics 
of a $2 \times 16$ character LED display, 2 toggle switches, 5 press buttons and a potentiometer (Figure 8). The changing of the direction of rotation and the enabling or disabling of driving is possible with the help of toggle switches.

The shearing velocity can be changed step by step between $0.075 \mu \mathrm{m} / \mathrm{s}$ and $156.25 \mu \mathrm{m} / \mathrm{s}$ and the displacement in a range of $0-25 \mathrm{~mm}$ with a precision of $1 \mu \mathrm{m}$. All parts of the controlling electronics are placed in a sheet cabinet and the user interface is on its face. The measurement system of the appliance is a separate module. The displacement is measured by an HBM WETA 1/10 inductive economic displacement transducer, the shear force by an HBM U9B $5 \mathrm{kN}$ force transducer. The Spider 8 and the Catman 4.5 software carry out the data acquisition.

\subsection{Testing of the apparatus}

The first tests were made with polyamide probes. The aim of these was checking of the constant velocity and performing constant velocity shear tests. In case of velocity checking, the shear test was made with zero normal load, and the displacement was measured as a function of time:

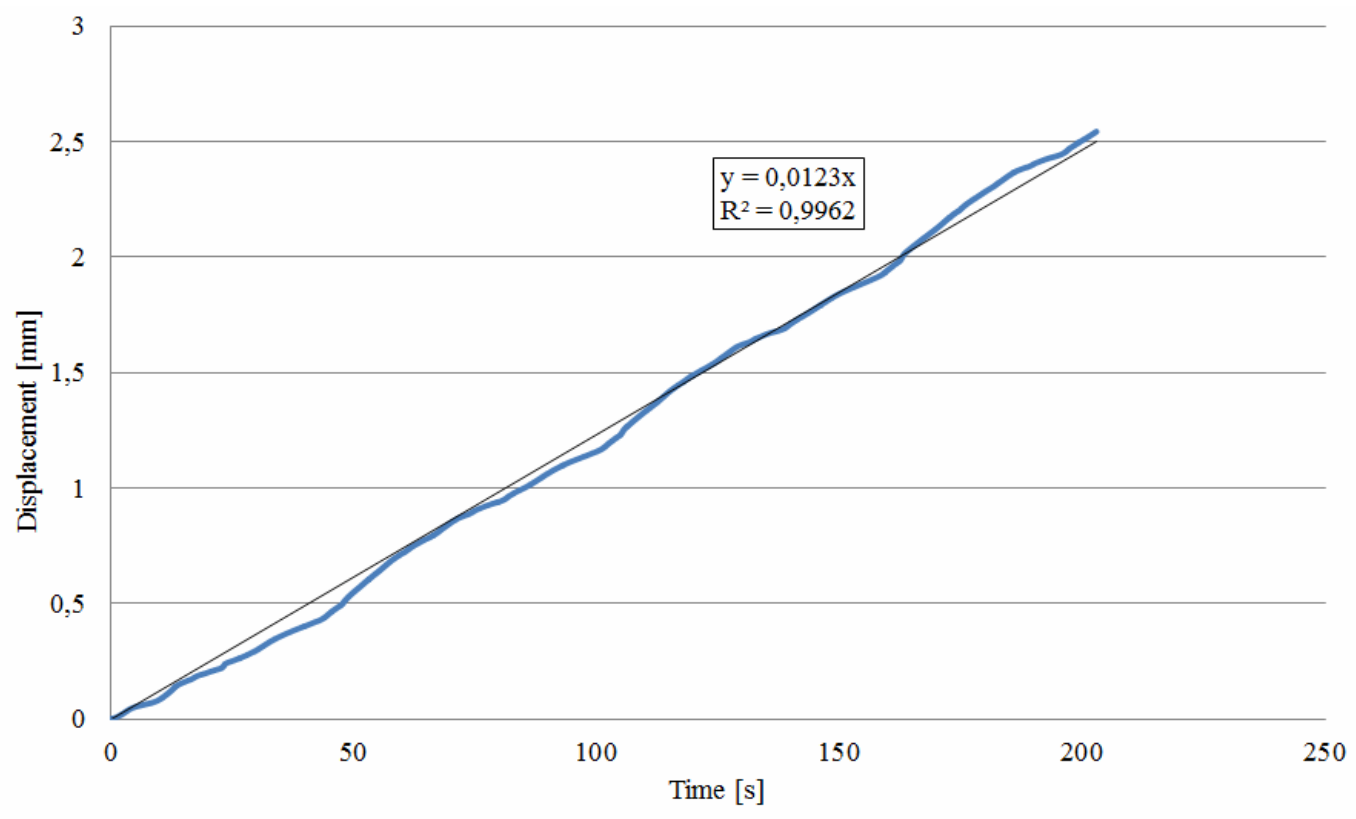

Fig. 9. The displacement as function of time with zero normal load 
During this test, a velocity of $12.5 \mu \mathrm{m} / \mathrm{s}$ was set. Based on the results of the linear regression the real velocity of the moving part was $12.3 \mu \mathrm{m} / \mathrm{s}$, hence the difference between the set and the real velocity is $1.6 \%$. Because the measured data and the theoretical values are in good relation, the shear velocity is constant in an unloaded case.

\section{Results}

After these results, other tests were made with a given normal stress and various sliding velocities. During these investigations, the sliding velocity was changed between $1-75 \mu \mathrm{m} / \mathrm{s}$ in 8 steps. The normal stress was $\sigma_{1}=200 \mathrm{kPa}$. The sampling rate was $10 \mathrm{~Hz}$ in both cases. Experimental measurements were carried out with polyamide and steel probes. The following diagrams show some results. The aims of these tests were to prove the reproducibility of the results and establish the performance limits of the shear tester.

The usual experimental protocol for evaluating rate and state dependent friction changes the shear velocity in a stepwise manner under constant normal stress. Normal stress was held constant during the measurements, which were ensured by the force regulated INSTRON 5581 universal material testing machine. Multiple velocity tests were carried out with constant shear velocity for a predetermined displacement, then suddenly changed to a different velocity and held constant for a while and changed back to the first velocity again. The tests were carried out with two different speed settings, 4.4-43.6 and 10.1-79.91 $\mu \mathrm{m} / \mathrm{s}$, for steel probes. Additionally, the different normal stress level was $200 \mathrm{kPa}$. During the tests, the shear force and the displacement were measured and the shear diagrams were determined (Figure 11). The purpose of these multiple velocity tests was to look at the time dependent friction coefficient, as seen in the earlier rock friction experiments of Dietrich. In these earlier works, two different velocity effects were observed, the step increase of shear velocity results in an immediate jump in frictional coefficient followed by displacement dependent decay and stabilization at a new steady-state friction. The reverse is seen if the shear speed is decreased. This friction coefficient jump on the higher speed level and the decrease on lower speed level can be seen on the shear diagrams (Figure 11). 

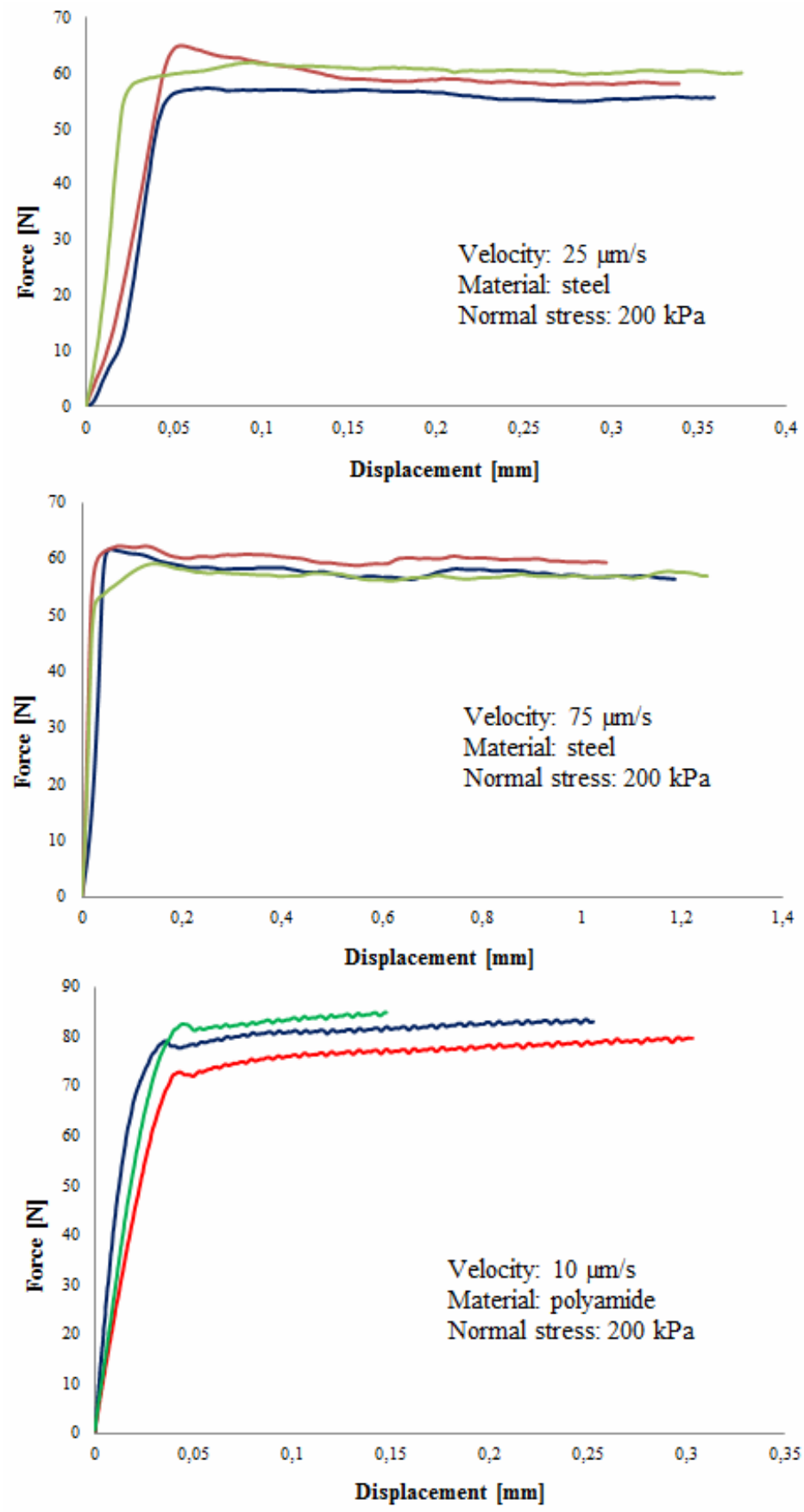

Fig. 10. The shear diagrams 

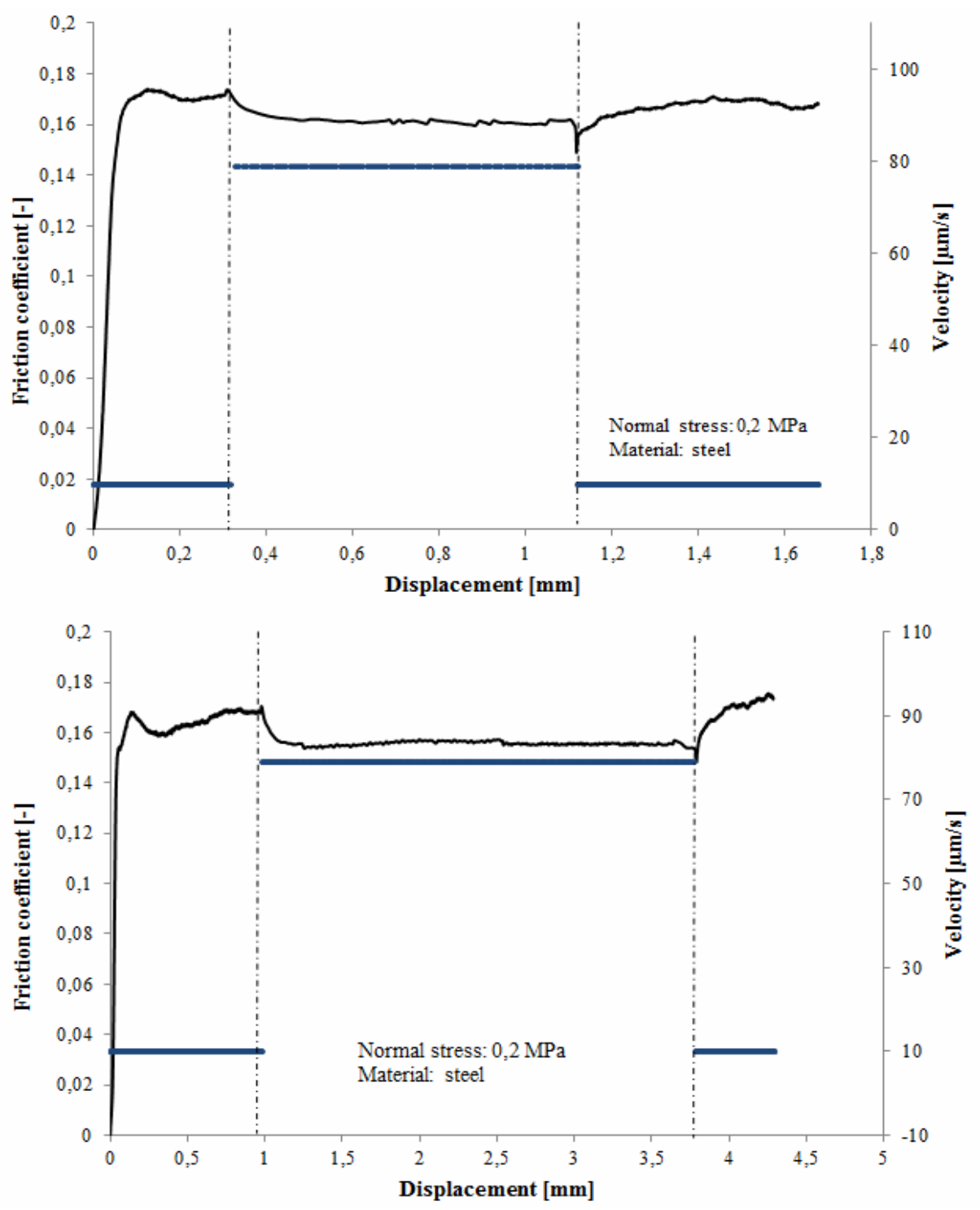

Fig. 11. Friction coefficient in function of displacement

Step changes of velocity result in residual and transient changes in friction coefficient. Firstly, at constant sliding velocity, it has proceeded for a sufficient distance for $\mu$ to have stabilized at a residual value $\left(\mu_{1}\right)$ then due to the sudden increase of velocity it produces an immediate increase in 
friction coefficient, then this is followed by a decrease $\left(\mu_{2}\right)$ to a new residual value. This new residual value is generally less than the residual coefficient on the previous slower velocity phase. After predetermined sliding displacement, the shear velocity abruptly decreases to the previously lower level and results in a positive jump in the friction coefficient to a new residual value $\left(\mu_{3}\right)$, which is greater than the residual coefficient at the first phase of the test with the same sliding velocity.

\section{Conclusion}

Rate and state dependent friction process can be observed in case of polymers, rocks, granular materials and even in the case of metals. In this work, the development of a testing apparatus is shown, which is performed sufficiently well to detect these time and velocity dependent friction phenomena. Based on our experimental tests with polyamide and steel, this apparatus is suitable to examine rate and state dependent friction, namely very similar characteristics were measured than can be found in literature. Our plan is to further improve the performance of the apparatus, in order to measure reliably the corresponding material parameters.

\section{Acknowledgment}

This paper was supported by the János Bolyai Research Scholarship of the Hungarian Academy of Sciences.

\section{Nomenclatures}

$\begin{array}{lll}A & \text { experimentally determined constant } & - \\ B & \text { experimentally determined constant } & - \\ c & \text { cohesion } & \mathrm{kPa} \\ d_{2} & \text { effective diameter } & \mathrm{mm} \\ \mathrm{F}_{\max } & \text { highest force } & \mathrm{N} \\ M_{\max } & \text { highest torque } & \mathrm{Nm} \\ V & \text { sliding velocity } & \mu \mathrm{m} / \mathrm{s} \\ V & \text { normalized sliding velocity } & \mu \mathrm{m} / \mathrm{s}\end{array}$




$\begin{array}{lll}a & \text { profile angle } & \circ \\ \theta & \text { state variable } & - \\ \theta^{*} & \text { normalized state variable } & - \\ \mu & \text { friction coefficient } & - \\ \mu_{0} & \text { experimentally determined constant } & - \\ \rho^{\prime} & \text { modified friction angle } & \circ \\ \sigma & \text { normal stress } & \mathrm{kPa} \\ \tau & \text { shear strength } & \mathrm{kPa} \\ \varphi & \text { internal friction angle } & \circ \\ \varphi_{r} & \text { residual friction angle } & \circ\end{array}$

\section{References}

Csatár, A., Safranyik, F., Bércesi, G. (2013) A NEW direct shear testing apparatus for the examination of the velocity- and time-dependent friction, Hungarian Agricultural Engineering, Vol. 25, pp. 54-58.

Dietrich, J. H. (1979) Modeling of rock friction I., Experimental results and constitutive equations, Journal of Geophysical Research, Vol. 84, pp. 2161-2168.

Dietrich, J. H. (1981) Constitutive properties of faults with simulated gouge, Geophysical Monograph Series, Vol. 24, pp. 103-120.

Dietrich, J. H., Kilgore, B. D. (1994) Direct observation of frictional contacts: New insights for state-dependent properties, Pure and Applied Geophysics PAGEOPH, Vol. 143, pp. 283-302.

Dowson, D. (1979) History of tribology. Longman, New York.

Mitsui, N., Ván, P. (2014) Thermodynamic aspects of rock friction, Acta Geodaetica et Geophysica, Vol. 49, pp. 135-146 (arXiv:1312.4930 [physics.geo-ph]).

Ruina, A. L. (1983) Slip instability and state variable friction laws, Journal of Geophysical Research, Vol. 88, pp. 10359-10370.

Ván, P. (2010) A képlékenység termodinamikája. In: Fülöp T. (ed.) Idő és térderiváltak anyagtörvényekben. Mérnök geológia-Közetmechanika Kiskönyvtár 10, Múegyetemi Kiadó, Budapest, pp. 15-50.

Ván, P., Mitsui, N., Hatano, T. (2015) Non-equilibrium thermodynamical framework for rate- and state-dependent friction, Periodica Polytechnica Civil Engineering, Online First paper 8249. DOI: 10.3311/PPci.8249 (arXiv:1501.04608).

Wang, Q. J., Chung, Y.-W. (2013) Encyclopedia of Tribology. Springer Science+Business Media, New York. 